\title{
A Invenção do Sete de Setembro, 1822-1831
}

The Invention of Sete de Setembro,

1822-1831

\section{Hendrik Kraay}

Professor no Departamento de História da Universidade de Calgary

(Calgary / Canadá)

e-mail:kraay@ucalgary.ca
As seguintes abreviaturas são usadas nas notas: CLB (Coleção das Leis do Brasil), NARS (National Archives and Records Service, Estados Unidos), PRO/FO (Public Record Office, Foreign Office, Grã-Bretanha), RIHGB (Revista do Instituto Histórico e Geográfico Brasileiro).

\section{Resumo}

Utilizando-se de jornais coevos, relatos de viajantes e relatórios de diplomatas estrangeiros, este artigo analisa a rápida invenção do Grito do Ipiranga, de D. Pedro I, em 7 de setembro de 1822 como o dia da independência do Brasil. Contrariamente àqueles que argumentam ter levado algum tempo para que as ações de D. Pedro naquele dia fossem consideradas como o momento fundador da nação brasileira, este artigo defende que foi em 1823 que se reconheceu a data como o dia da independência do Brasil. No entanto, até o final da década de 1820, esse dia foi considerado menos importante como festividade nacional que 012 de outubro, aniversário do imperador, comemoração de sua aclamação em 1822, e, consequentemente, o dia em que o império brasileiro foi criado. Conclui-se o presente texto com uma discussão sobre as importantes mudanças, em 1830, no significado dos dois dias e a extinção do 12 de outubro, em 1831, como um dia de festividade nacional, o que deixou o 7 de setembro como o feriado nacional mais importante do Brasil.

\begin{abstract}
Using contemporary newspapers, travelers accounts, and the reports of foreign diplomats, this article examines the rapid invention of D. Pedro I's 7 September 1822 Grito do Ipiranga as Brazil's independence day. Contrary to those who have argued that it took some time to construct D. Pedro's actions that day as the Brazilian nation's founding moment, this article argues that, in fact, the day was recognized as Brazil's independence day in 1823. However, for much of the rest of the 1820s, it was considered less important a day of national festivity than 12 October, the emperor's birthday and the commemoration of his acclamation in 1822, and consequently the day on which the Brazilian empire was created. This article concludes with a discussion of the significant changes in the meaning of both days in 1830 and the abolition of 12 October as a day of national festivity in 1831, which left 7 September as Brazil's most important national holiday.
\end{abstract}

\section{Palavras-chave}

identidade nacional, representações políticas, Rio de Janeiro, Independência, festas cívicas, Primeiro Reinado

\section{Keywords}

national identity, political representation, Rio de Janeiro, Independence, civic rituals, First Reign 
HANDELMANN, Gottfried Heinrich. História do Brasil. 2 vols. Tradução do Instituto Histórico e Geográfico Brasileiro. Rio de Janeiro: IHGB, 1931 vol.2, p.792, nota 171. A análise mais detalhada sobre essa questão é de LYRA, Maria de Lourdes Viana. Memória da Independência. Marcos e representações simbólicas. Revista Brasileira de História, São Paulo, n.29, p.177-89, 1995. Ver também NEVES, Lúcia Maria Bastos Pereira das. Corcundas e constitucionais: a cultura politica da Independência (1820-1822). Rio de Janeiro: FAPERJ e Revan, 2003, p.369-370; OLIVEIRA, Cecilia Helena de Salles. 0 Museu Paulista da USP e a memória da Independência. Cadernos Cedes, n.22, p.66-67, dezembro de 2002. LYRA, Maria de Lourdes Viana. Op.Cit. p.198, 201.

Ibidem. p.191-197.

\section{Introdução}

Atualmente, é um axioma nacional a proclamação da independência brasileira por D. Pedro I em 7 de setembro de 1822, às margens do Ipiranga, em São Paulo. Naquele ano, entretanto, o significado histórico de suas ações não era tão evidente e, pelo menos até o final de 1822, contemporâneos atribuíram pouco significado à data e ao Grito do Ipiranga, pois se ocupavam com a aclamação do imperador (12 de outubro) e sua coroação ( $1^{\circ}$ de dezembro). Daí resultou um consenso historiográfico de que demorou algum tempo para que o Sete de Setembro se tornasse o dia da independência do Brasil e de que a data não tinha grande significado senão bem depois de 1822. Neste artigo, trago novas fontes para essa discussão e argumento que, na realidade, o 7 de setembro foi reconhecido como o dia da independência do Brasil em 1823 e que sua celebração ganhou relevância rapidamente, pelo menos no Rio de Janeiro, apesar de o 12 de outubro ter permanecido o "dia de festa nacional" mais importante na maior parte da década.

Já em 1860, Gottfried Heinrich Handelmann observou, sobre o 7 de setembro, que "a principio não se Ihe ligou tanta importância como depois"; contudo, não ofereceu fontes para embasar tal afirmação. Uma série de outros historiadores tem destacado, recentemente, a pouca atenção que a imprensa do Rio de Janeiro despendeu aos eventos do 7 de setembro de 1822 nos anos subsequentes à independência, a ausência da data em uma lista de dias de gala da corte publicada em dezembro e a inexistência de comentários de Hipólito José da Costa sobre a data em seu Correio Brasiliense (entre outras coisas); o que parece surpreendente, considerando-se a importância atribuída posteriormente ao Sete de Setembro. ${ }^{2}$ Em 1995, Maria de Lourdes Viana Lyra publicou um artigo no qual afirmava que a construção do 7 de setembro como o dia da independência do Brasil havia começado em meados da década de 1820 e sido concluida até 1830, com a publicação da História dos principais sucessos do Império do Brasil, de José da Silva Lisboa, uma história oficial em que o Visconde de Cairú apresenta Pedro como "responsável único pela decisão de tornar o Brasil livre", uma avaliação que "atendia com perfeição à memória que se queria firmar: a ruptura da unidade luso-brasileira e a conseqüente independência absoluta do Brasil constituiram atos exclusivos da vontade do imperador-herói, que tudo fizera para defesa da liberdade do seu povo". ${ }^{3}$

Essa é uma interpretação conservadora da independência e, como Lyra explica, Cairú respondia ao grande debate dos anos da década de 1820 com relação às origens da soberania de Pedro l: as posições reformista e conservadora sustentavam que ela derivava da linhagem real do imperador, enquanto a visão revolucionária defendia que apenas o povo - a nação brasileira - tinha o direito de aclamar Pedro como seu governante e investi-lo de poder. Pedro teve que renunciar formalmente ao seu título no tratado de 1825, que resultou no reconhecimento português, para governar com base na soberania popular, o que, por sua vez, exigiu uma reconstrução da história da independência, devidamente enunciada por Cairú, para enfatizar que ela se originou diretamente das ações de Pedro no 7 de setembro de 1822 e não por meio de sua aclamação pela nação brasileira. ${ }^{4}$

A elegante análise de Lyra, entretanto, falha na medida em que a interpretação de Cairú foi contestada por muitos daqueles que comemoraram o Sete de Setembro em 1830. Além disso, um olhar mais atento às reais celebrações ocorridas no 7 de setembro a partir de 1823 (conforme descrito por diplomatas estrangeiros, por alguns viajantes e 
Decreto, 21 de dezembro de 1822, CLB. Esta análise da legislação sobre dias de gala segue um panfleto pouco conhecido de COSTA, Luiz Monteiro da. D. Pedro I entre o 7 de setembro e o 12 de outubro. Salvador: Imprensa Oficial da Bahia, 1956. Agradeço a Marco Morel a indicação deste texto.

Decreto, 10 de dezembro de 1822, CLB.

Falla com que Sua Magestade o Imperador abriu a Assembléa Geral Legislativa Constituinte no dia 3 de Maio de 1823, CLB.

Sessões de 5 e 9 de setembro de 1823. BRASIL, Diário da Assembléa Geral Constituinte e Legislativa do Império do Brasil, 1823. Ed. facsimilar, 4vols. em 2. Brasilia: Senado Federal, 1972, vol.1, p.722, 733

Condy Raguet ao Secretário de Estado, Rio de Janeiro, 8 de setembro de 1823, NARS, T-172, rolo 2

10

"Prepara-se para o 7 de setembro, como o dia do aniversário da proclamação da independência em São Paulo, uma festa militar." Wenzel de Mareschal ao Principe de Metternich, Rio de Janeiro, 30 de agosto de 1823. RIHGB, n.314, p.346, janeiro-março de 1977. Ver também Mareschal a Metternich, Rio de Janeiro, 20 de setembro de 1823. RIHGB, n. 315, p.308, abriljunho de 1977.

"Soneto ao Faustissimo Anniversario da Independencia Brasileira," O Sylpho, 13 de setembro de 1823. na imprensa) revela indubitavelmente que esse já era considerado dia da independência do Brasil. Mais precisamente, a questão primordial era se a independência, conforme proclamada no 7 de setembro, foi tão importante quanto a aclamação de Pedro no 12 de outubro (ou mesmo quanto outros eventos que estabeleceram a ordem política imperial). A julgar pelas comemorações ocorridas no Rio de Janeiro, o Sete de Setembro foi, por um curto período, ofuscado pelo 12 de outubro, mas, em meados da década, já viria a obter a mesma importância. Uma segunda questão, bastante debatida em 1830 e 1831, foi a natureza do papel de Pedro no 7 de setembro de 1822; muitos, na verdade, rejeitaram a visão de Cairú e argumentaram que a proclamação da independência por Pedro seguiu o desejo da nação de ser livre.

\section{Celebrando o 7 de Setembro e o 12 de Outubro, 1823-1825}

Para o Rio de Janeiro, os eventos da segunda metade de 1822 que levaram à criação de um império brasileiro independente ofereceram duas alternativas principais com que era possivel datar a fundação do novo regime: 0 Grito do Ipiranga em 7 de setembro ou a aclamação de Pedro em 12 de outubro (a mesma data de seu aniversário). Não estava claro qual desses dias era mais digno de comemoração. Um decreto de dezembro de 1822 determinando o protocolo da corte para os dias de gala deixou de mencionar o 7 de setembro e, o que talvez seja ainda mais interessante, não identificou um dia para comemorar a independência (12 de outubro foi descrito como a data do aniversário de Pedro e de sua aclamação). ${ }^{5}$ No início daquele mês, no entanto, Pedro havia decretado que "sendo conveniente memorizar a gloriosa época da Independência do Brasil e sua elevação à categoria de Império [...] o número de anos que decorreram da mencionada época [...] deverá contar-se de o memorável dia 12 de outubro do presente ano".6

No ano seguinte, contudo, o 7 de setembro rapidamente ganhou notoriedade. Durante a fala do trono que abriu a Assembleia Constituinte em 3 de maio de 1823, Pedro aludiu à data como a sua primeira declaração em favor da completa independência. ${ }^{7}$ No início de setembro, a assembléia decidiu que o dia fosse considerado, temporariamente, feriado nacional, por ser o aniversário da independência brasileira, e enviou uma grande delegação para parabenizar Pedro. ${ }^{8}$ Para a surpresa de Condy Raguet, embaixador dos Estados Unidos no Brasil, o 7 de setembro de 1823 "foi celebrado com toda a pompa militar, civil e religiosa apropriada a uma festa tão importante". Ele especulou que a cerimônia se devesse à política cada vez mais acirrada relativa à assembleia e se questionou se andara equivocado ao ver a aclamação (12 de outubro) como "o verdadeiro dia de declaração da independência".9 0 Barão Wenzel de Mareschal, representante austríaco, não estava, aparentemente, surpreso e simplesmente relatou que "se prepara para o 7 de setembro, como o dia do aniversário da independência proclamada em São Paulo, uma festa militar".10 Naquele ano, a única alusão à comemoração do 7 de setembro na imprensa do Rio de Janeiro foi um soneto em 0 Sylpho, que conclui: "Estás independente ... oh! que te resta/Valor Brasil! Constituição ou Morte."11 Os elementos "militar, civil e religioso" da celebração a que se referiu Raguet eram constitutivos das grandes festas cívicas daquela época - saudações da artilharia dos fortes e navios de guerra, uma parada militar, um Te Deum na capela imperial, um cortejo no Paço da Cidade (com a cerimônia obrigatória do beija-mão), uma noite de gala no teatro e iluminação noturna da cidade. 
12

Sessões de 7, 9 e 13 de outubro de 1823. Brasil, Diário da Assemblea, vol.2, p.186-187, 214, 231 232.

13

FERNANDES, José Pedro. Elogio no muito fausto natalicio, e anniversario da Gloriosa acclamação de sua magestade Imperial o Senhor D. Pedro Primeiro, Imperador Constitucional e defensor perpetuo do Brasil, recitado no theatro de S. João. Rio de Janeiro: Typ. da Silva Porto, 1823. Para uma descrição das comemorações do dia 12 de outubro de 1823, ver Mareschal a Metternich, Rio de Janeiro, 21 de outubro de 1823. RIHGB, n. 315, p.319, abril-junho de 1977 .

\section{4}

Decisão 155 (Império), 23 de outubro de 1823; Decisão 159 (Império), 10 de novembro de 1823, $C L B$.

\section{5}

"Almanaque do Rio de Janeiro para o ano de 1824". RIHGB, n. 278, p.201, janeiro-março de 1968.

\footnotetext{
16

Raguet ao Secretário do Estado, Rio de Janeiro, 12 de setembro de 1824, NARS, T-172, rolo 3; 0 Spectador Brasileiro, 10 de setembro de 1824; Mareschal a Metternich, Rio de Janeiro, 18 de setembro de 1824. RIHGB, n. 323, p.200, abriljunho de 1979.

17

"Rio de Janeiro, 10 de Setembro 1822 [sic]," 0 Spectador Brasileiro, 10 de setembro de 1824

18

Decisão 210 (Guerra), 10 de outubro de 1824, CLB.

19

Ver as listas dos despachos publicadas em 0

Spectador Brasileiro, 15 e 18 de outubro de 1824.
}

Um mês depois, os deputados designaram, da mesma maneira, o 12 de outubro como um dia de festividade nacional. Tiveram, no entanto, alguma dificuldade para determinar o que eles propunham que fosse celebrado - a aclamação de Pedro, seu aniversário ou, como Nicolau Pereira de Campos Vergueiro (deputado de São Paulo) definiu, "o aniversário da aclamação do império ou da sua criação." Em sua mensagem de felicitações ao monarca, os deputados enfatizaram o caráter constitucional do império, refletindo as crescentes tensões entre o órgão e Pedro. ${ }^{12} 0$ dia foi tão comemorado quanto o 7 de setembro e alguns tomaram conhecimento da outra data de festividade nacional. Na noite de gala do teatro, José Pedro Fernandes recitou um elogio, no qual identificou o Grito do Ipiranga como o momento de fundação do Brasil: "... aparece de repente/Formidável Nação, válido Império/Ä voz de PEDRO, ao grito "INDEPENDÊNCIA"/Que trovejou nas margens do Piranga"; uma visão que teria soado como música aos ouvidos de Cairú. ${ }^{13}$ Naquele ano, e na maioria das celebrações do 12 de outubro subsequentes, Pedro concedeu promoções nas forças armadas e títulos de nobreza e outras recompensas aos seus súditos.

Em uma decisão emitida em 23 de outubro, Pedro declarou o 7 de setembro e o 12 de outubro como dias equivalentes de festividade nacional, sancionando, desse modo, a intenção da assembléia constituinte. 0 Sete de Setembro foi descrito como o dia "em que o mesmo A[ugusto] S[enhor] tomou a sublime resolução de proclamar pela primeira vez a Independência do Brasil no sítio do Piranga", enquanto o 12 de outubro era o "faustíssimo anniversário da aclamação de S. M. o Imperador". Algumas semanas depois, outra decisão esclareceu que o 12 de outubro também celebrava a "grandiosa elevação do Brasil à categoria de Império e ... o anniversário natalício do mesmo A[ugusto] S[enhor]."14 0 Almanaque da cidade do Rio de Janeiro para 1824 listou ambos como dias de grande gala e explicou seus respectivos significados conforme descrito nos dois decretos. ${ }^{15}$

Não obstante a decisão de 1823, 07 de setembro permaneceu subordinado ao 12 de outubro durante os dois anos seguintes. Em 1824, Raguet relatou que o 7 de setembro "foi anunciado e celebrado como o segundo aniversário da Declaração da Independência do Brasil, mas certamente não com a pompa... e magnificência" do 12 de outubro, acrescentando que, "nesta última celebração, o povo não tinha participação". O Spectador Brasileiro, da mesma forma, proclamou ser o 7 de setembro o "Anniversário da Independência Política do Império Constitucional do Brasil", mas nenhum jornal relatou as celebrações de 1824. Na verdade, havia pouco a ser relatado; Mareschal contou que, por razões não especificadas, não houve cortejo e beija-mão e o mau tempo forçou o cancelamento do desfile militar. ${ }^{16}$ Em contraste, 0 Spectador Brasileiro aguardava ansiosamente pela "brilhante solenidade" que estava sendo preparada para o 12 de outubro e contava que o dia fosse comemorado por todo o império ${ }^{17}$. 0 ministro da guerra fez preparativos para saudações da artilharia em toda a costa do Rio de Janeiro e ordenou à milícia da província que também desfilasse, tudo em homenagem à Pedro e a sua "Gloriosa Acclamação e de seu Natalicio".18 Infelizmente, não encontrei descrições dessas comemorações, mas Pedro, como de costume, emitiu vários despachos. ${ }^{19}$

As três decisões relativas ao protocolo nos dias de gala emitidas pelo ministério da guerra entre março e setembro de 1825 têm sido evocadas como índices das dúvidas constantes sobre a importância do 7 de setembro, mas podem muito bem apenas revelar confusão burocrática. Em março, 0 
20

Decisão 38 (Guerra), 7 de março de 1825; Decisão 187 (Guerra), 25 de agosto de 1825; Decisão 198 (Guerra), 5 de setembro de 1825 (Guerra), CLB. Costa analisou as duas primeiras dessas decisões mas desconhecia a terceira, $D$. Pedro I, p. 23-27.

\section{1}

Henry Chamberlain a George Canning, Rio de Janeiro, 8 de setembro de 1825, PRO/FO 13, vol.10, fol.48v; SCHLICHTHORST, C[arl] 0. 0 Rio de Janeiro como é, 1824-1826 (huma vez e nunca mais). Tradução de Emmy Dodt e Gustavo Barroso. Rio de Janeiro: Ed. Getúlio Costa, 1943, p.197.

22

Raguet ao Secretário do Estado, Rio de Janeiro, 15 de setembro de 1825, NARS, T-172, rolo 3.

23

MONTEIRO, Tobias. História do Império: o Primeiro Reinado. 2vols. Belo Horizonte: Itatiaia; São Paulo: EDUSP, 1982, vol.1, p.277-279, 281; LYRA, Maria de Lourdes Viana. Memória da Independência. Marcos e representações simbólicas. Revista Brasileira de História, São Paulo, n.29, p.190-194, 1995; SOUSA, Octávio Tarquinio de. A vida de D. Pedro I. 3vols. Belo Horizonte: Itatiaia; São Paulo: Edusp, 1988, vol.2, p.177, 186-189.

\section{4}

Mareschal a Metternich, Rio de Janeiro, 24 de outubro de 1825. RIHGB, n. 335, p.157, abriljunho de 1982; Raguet ao Secretário do Estado, Rio de Janeiro, 26 de outubro de 1825, NARS, M-121, rolo 6; Chamberlain a Canning, Rio de Janeiro, 15 de outubro de 1824, PRO/FO 13, vol.10, fol.239.

25

SCHLICHTHORST, C[arl] 0. Op.Cit. p.248. ministério ordenou que o 7 de setembro fosse celebrado da mesma forma que o 25 de março (o aniversário do juramento à constituição); em outras palavras, nesses dias de grande gala, os fortes deveriam hastear as bandeiras e disparar três rodadas de vinte e uma saudações. Esse decreto, entretanto, omitiu o 12 de outubro. Em agosto, o 7 de Setembro foi rebaixado à classificação de "pequena gala", a ser comemorada apenas com bandeiras, enquanto o 12 de outubro foi designado como "dia de grande gala", a ser comemorado com três saudações de 101 tiros e uma grande parada. Dez dias depois, o 7 de Setembro foi promovido novamente à categoria de grande gala, a ser celebrado conforme ordenado na decisão de março. 20

Em 1825, o 7 de Setembro coincidiu com o anúncio do reconhecimento do Brasil pela Grã-Bretanha, o que tornou possivel a Carl 0 . Schlichthorst declarar que essa era "a data mais importante da história do Brasil imperial". 21 Pedro distribuiu pessoalmente, das janelas do palácio, cópias do tratado antes do cortejo e removeu publicamente o emblema de Independência ou Morte que ele havia usado desde 1822.22 Diplomatas franceses e austríacos relataram pouco entusiasmo por essas celebrações, já que os termos do tratado, na realidade, minaram o princípio da posição de Pedro como imperador por aclamação popular. ${ }^{23}$ Mareschal relatou que as celebrações habituais ocorreram em 12 de outubro, Raguet fez referência à "grande pompa" e Henry Chamberlain, o ministro britânico, mencionou as "concessões de favor sem precedentes, incluindo títulos, honrarias e promoções, a um grau que se poderia quase ser chamado pródigo".24 Schlichthorst afirmou que 10.000 tropas desfilaram no Campo de Santana, mas observou que essa foi a última dessas grandes exibições militares, pois muitos dos soldados foram enviados a Montevidéu logo depois. 25

Essa exposição das fontes disponiveis sobre a comemoração do 7 de setembro e do 12 de outubro no período de 1823-1825, muitas das quais inacessiveis para aqueles historiadores que escreveram sobre as origens do 7 de Setembro, revela claramente que, se teve pouca importância para seus contemporâneos em 1822, essa data emergiu rapidamente como o dia da independência do Brasil, embora permanecesse secundária em relação ao 12 de outubro. 0 significado desses dois dias, no entanto, continuou oscilante. Ambos, é claro, evocavam Pedro como monarca e herói, mesmo que pudessem ser vistos como personificação das origens populares do império. A aclamação de Pedro pelo povo em 12 de outubro contrariou profundamente a conservadora Santa Aliança e complicou a busca do Brasil pelo reconhecimento internacional. Mas o dia também poderia ser celebrado apenas como o aniversário de Pedro ou como o dia em que o Brasil se tornou um império, conceitos menos problemáticos. Para que 07 de setembro conotasse o momento de fundação do Brasil, o grito de "Independência ou Morte" tinha que repercutir na população ou ressoar do Amazonas ao Rio da Prata, um tropo recorrente utilizado na retórica do 7 de setembro. Por fim, o 7 de setembro ofereceu uma visão popular ou populista da independência mais prontamente que o 12 de outubro, embora essa distinção não tenha ficado totalmente clara até 1830.

\section{Legislando sobre Dias de Festa Nacional}

$\mathrm{Na}$ primeira sessão do parlamento brasileiro, os legisladores instituíram cinco dias de festividade nacional, quatro dos quais estavam diretamente ligados ao Imperador Pedro I: 9 de janeiro (data em que decidiu ficar no Brasil, em 1822), 25 de março, 3 de maio (dia de abertura da sessão 
Lei, 9 de setembro de 1826, CLB. Este e o parágrafo seguinte são baseados nos debates em Anais do Senado, 1826, vol.1, p.85; vol.2, p.100-102; vol.3, p.14-16, p.122-129; e Anais da Câmara dos Deputados, 1826, vol.2, p.36; vol.3, p.262-265.

27

Não há indícios de que a Assembléia Constituinte propôs designar o 9 de janeiro como dia de festa nacional. legislativa anual), 7 de setembro e 12 de outubro. ${ }^{26}$ Os debates no senado e na câmara dos deputados revelaram uma importante diferença entre as duas casas em suas respectivas visões sobre a natureza política do império. Nesse debate, entretanto, estava claro que o Sete de Setembro era considerado por muitos o dia da independência do Brasil, mas alguns ainda o viam como relativamente menos importante em comparação com o 12 de outubro.

No senado, o visconde de Nazaré propôs, em 10 de maio, que o dia 13 fosse declarado "festa nacional" (naquela data, em 1822, Pedro havia aceitado o título de "defensor perpétuo"). Essa moção - não aprovada levou a um projeto de lei que propôs oito "dias de festividade nacional": 9 de janeiro (quando Pedro decidiu, em 1822, ficar no Brasil, o Dia do Fico) e 22 de janeiro (dia do aniversário da imperatriz), 25 de março, 13 de maio, 7 de setembro, 12 de outubro, $1^{\circ}$ de dezembro (coroação de Pedro) e 2 de dezembro (aniversário do provável herdeiro, o futuro Pedro II). Nazaré justificou seu projeto de lei com base no argumento de que "todas as nações recomendaram sempre à posteridade os dias notáveis de suas instituições." Oito feriados eram demais para o visconde de Barbacena, que notou que todos eles se referiam de alguma forma a Pedro I, propondo, então, que se mantivesse apenas o 12 de outubro. Considerando que a assembléia constituinte havia proposto 3 feriados (9 de janeiro, 7 de setembro e 12 de outubro), 27 o visconde de Caravelas defendeu o 7 de setembro como "o dia, em que o Imperador quebrou as nossas prisões, as cadeias que nos ligavam a Portugal, em que declarou a independência, e foi seguida a sua voz por todo o Brasil", recomendando fortemente, também, a manutenção do 25 de março. Na segunda leitura, a visão de Barbacena prevaleceu: 12 de outubro, explicou ele, "encerra a particularidade de reunir os mais gloriosos fatos do Brasil". Nazaré, que perdeu essa seção, lamentou, na terceira leitura, que seus colegas senadores "mutilaram" o seu projeto de lei. Ao argumento de Barbacena, ele retrucou que um único feriado celebrando todos os atos de Pedro I seria uma "mera ficção", e que muitos feriados eram necessários para que "futuras gerações, ouvindo as salvas, vendo embandeiramentos, e mais demonstrações de regosijo próprios de semelhantes dias, se lembrem dos gloriosos fatos, que nele se passaram." Apenas com muitas celebrações os brasileiros lembrariam a história de sua nação, acrescentou Caravelas (agora apoiando Nazaré), uma vez que poucos homens no Brasil leem livros de história e, ao contrário dos antigos, o Brasil não tinha monumentos públicos; por esta razão, eram essenciais os festivais a que a população pudesse assistir. No final, os senadores convieram em uma lista de quatro feriados (9 de janeiro, 25 de março, 7 de setembro e 12 de outubro), mas Nazaré, Caravelas e outros quatro senadores registraram seus votos contra o projeto de lei.

0 projeto foi, então, para a câmara dos deputados, onde Manoel de Souza Franco, do Rio de Janeiro, em meio a sonoros aplausos, sugeriu fortemente a inclusão de 3 de maio, data na qual, segundo a constituição, o parlamento se reuniu. A legislatura, salientou ele, era ao menos tão importante quanto o executivo (a monarquia), celebrado no projeto de lei do senado. Nicolau Pereira de Campos Vergueiro, de São Paulo, propôs uma emenda abandonando o 25 de março e o 7 de setembro e acrescentando o 3 de maio, baseando-se no argumento de que a legislatura era mais importante que a constituição e de que o 7 de setembro representava a proclamação da independência em apenas uma província. Bernardo Pereira 


\section{8}

O Spectador Brasileiro, 7 de setembro de 1826 ; Aurora Fluminense, 12 de outubro de 1829. Ver também Gazeta do Brasil, 7 de setembro de 1827; L Echo de I Amérique du Sud, 10 de setembro e 13 de outubro de 1827; Astrea, 14 de outubro de 1828; A Luz Brasileira, 13 de outubro de 1829; Jornal do Commercio, 13 de outubro de 1829. Para uma descrição das comemorações do dia 12 de outubro de 1829, ver HOLMAN, James. A Voyage Round the World, Including Travels in Africa, Asia, Australasia, America, etc., etc., from MDCCCXXVII to MDCCCXXXII. 4 vols. Londres: Smith, Elder, \& Co., 1834 , vol.2, p.58-59.

\section{9}

WALSH, Robert. Notices of Brazil in 1828 and 1829. 2 vols. Londres: Frederick Westley e A. H. Davis, 1830, vol. 2, p.419.

\section{0}

Aurora Fluminense, 27 de março de 1829; Jornal do Commercio, 28 de março de 1829. de Vasconcelos respondeu que o 3 de maio estava para o 7 de setembro assim como um pigmeu estava para um gigante. A independência, continuou ele, foi proclamada em 7 de setembro, totalmente ratificada em 12 de outubro e selada em 25 de março com a constituição; a abertura da legislatura apenas decorria dos outros três dias. Além disso, acrescentar outro feriado equivaleria a favorecer os funcionários públicos, que teriam mais um dia de folga. Outros deputados defenderam vigorosamente 0 3 de maio, uma vez que, conforme um deles colocou, a independência e a constituição teriam sido inúteis "se a representação nacional não fosse instalada." Tais argumentos convenceram, e o 3 de maio juntou-se aos quatro feriados monárquicos do senado.

Esse debate revela que o 7 de setembro ainda não tinha sido completamente aceito como o dia da independência do Brasil. Vergueiro, deputado de São Paulo, pôde caracterizá-lo apenas como um dia significativo no nível provincial, mas nem ele, nem outro legislador ofereceu um dia da independência alternativo. Para os senadores, a monarquia era mais importante que a legislatura, uma visão que os deputados contestaram com 0 aditamento do 3 de maio.

A lei de 1826 modificou a prática das festas cívicas no Rio de Janeiro e, nos anos seguintes, o 7 de setembro e o 12 de outubro passaram a ser comemorados igualmente, com todas as características dos primeiros anos do reinado de Pedro. Os jornais enfatizavam reiteradamente que esses dois feriados comemoravam a criação, por Pedro, da nação brasileira e de sua organização política com base constitucional. Ele era a "voz regeneradora que criou uma Nação" em 7 de setembro de 1822, declarou 0 Spectador Brasileiro, em 1826. Em 12 de outubro de 1829, os brasileiros celebraram muito mais do que apenas o aniversário de um "Rei absoluto", explicou o Aurora Fluminense; em vez disso, eles recordaram "o triunfo das doutrinas proclamadas pela civilisação [que] foi sancionado pelo descendente de vinte monarchas." 28

Significativamente, os outros três feriados designados por lei em 1826 não foram muito comemorados. 0 parlamento devidamente se reunia todo dia 3 de maio, mas os moradores da capital não celebravam esse dia. Robert Walsh surpreendeu-se com o pouco interesse pela abertura do parlamento, em 1829, ${ }^{29}$ enquanto o aniversário da decisão de Pedro em permanecer no Brasil passou quase despercebido. Não há indicações de que o 25 de março recebeu mais do que uma atenção superficial. Em 1829, o Aurora Fluminense mencionou o dia com um editorial que salientava a sorte do Brasil em ter um "Monarca, que os Povos haviam escolhido, [que] não hesitou em oferecer à aprovação dos Brasileiros um Código liberal, em que se achavam gravados todos esses sagrados foros", o que custou, em qualquer outro lugar, tanto sangue para ser alcançado. A Carta de 1824 foi, segundo Evaristo Ferreira da Veiga, editor liberal moderado desse jornal, "a mais liberal de todas as Constituições Monárquico-Representativas." Aparentemente, contudo, não houve comemoração pública desse dia, exceto por saudações da artilharia. ${ }^{30}$

Em 1830, em meio às nascentes tensões entre exaltados e defensores de Pedro I, as comemorações de dias de festividade nacional no Rio de Janeiro mudaram completamente quando, pela primeira vez, grupos não governamentais organizaram as festas civicas. As manifestações dos exaltados no 25 de março, em honra à constituição, foram um grande desafio para o imperador; e no 7 de setembro esses liberais radicais tentaram repetir o êxito 
31

KRAAY, Hendrik. Nação, Estado e política popular no Rio de Janeiro: rituais cívicos depois da Independência. In: PAMPLONA, Marco A., e DOYLE, Don H. (orgs.). Nacionalismo no Novo Mundo. Rio de Janeiro: Editora Record, 2008, p.329-354. Para uma perspectiva diferente, ver WISSER, William M. Rhetoric and Riot in Rio de Janeiro, 1827-1831. 2006. 265f. Tese (Doutorado em História). University of North Carolina at Chapel Hill. p.114-196.

32

Nova Luz Brasileira, 7 de setembro de 1830 .

33

Aurora Fluminense, 10 de setembro de 1830.

34

O Brasileiro Imparcial, 7 de setembro de 1830 .
35

GUIMARÃES, Lucia Maria Paschoal. Liberalismo moderado: postulados ideológicos e práticas políticas no periodo regencial (1831-1837). In: PEIXOTO, Antonio Carlos, et al. (orgs.). 0 liberalismo no Brasil imperial: origens, conceitos e prática. Rio de Janeiro: Editora Revan, 2001. p.107-12; BASILE, Marcelo Otávio Neri de Campos. O Império em construção: projetos de Brasil e ação política na Corte regencial. 2004. 490f. Tese (Doutorado em História Social). Universidade Federal do Rio de Janeiro, Rio de Janeiro, 2004, p.83-109.

\section{6}

Jornal do Commercio, 7 de setembro de 1831. Sobre estas comemorações, ver também BASILE, Marcelo Otávio Neri de Campos. Festas cívicas na Corte regencial. Varia História, Belo Horizonte, n.36, p.494-516, julho-dezembro de 2006.

37

0 Independente, 6 de setembro de 1831. Ver também Aurora Fluminense, 5 de setembro de 1831.

\section{8}

Aurora Fluminense, 9 de setembro de 1831.

39

Jornal do Commercio, 7 de setembro de 1831. Ver também Astrea, 6 de setembro de 1831; e 0 Independente, 9 de setembro de 1831. de março. Aqueles que apoiavam Pedro I responderam, no 12 de outubro, com pomposas comemorações de sua aclamação e de seu aniversário. Descrevi alhures essas celebrações e o extenso debate entorno delas, o que não repetirei aqui, salvo para enfatizar que foram manifestações políticas nas quais grupos adversários de defensores e opositores de Pedro I demonstravam publicamente suas diferentes visões sobre as origens da independência brasileira e sobre o papel adequado do monarca na ordem política. ${ }^{31}$ No 7 de setembro, o líder dos exaltados, Ezequiel Corrêa dos Santos, simplesmente ignorou Pedro I e declarou que a conquista da independência pelas nações "sempre há sido por elas contado como o único dia que é verdadeiramente do povo."32 0 moderado Evaristo da Veiga declarou que Pedro havia seguido a vontade dos brasileiros no 7 setembro de 1822: "Abraçou voluntariamente a nossa causa, declarou-se brasileiro também ... e tornou-se assim digno de reinar sobre os brasileiros por unânime escolha da nossa recente associação política."33 Líderes partidários de Pedro I, tal qual Joaquim José da Silva Maia, exortaram os brasileiros a serem dignos da independência e das instituições concedidas pelo "mais magnânimo dos monarcas."34. Enquanto o visconde de Cairú pode ter construído diligentemente uma versão conservadora do 7 de setembro em sua história da independência, encomendada oficialmente, e sua visão do Grito do Ipiranga como uma ação apenas da vontade de Pedro fora conveniente em uma monarquia conservadora, como Lyra argumentou, muitos discordaram de sua posição. Eles não rejeitaram o 7 de setembro, entretanto, como o dia da independência do Brasil; em vez disso, subordinaram Pedro à nação na sua avaliação do papel do imperador em 1822.

\section{Novos e Velhos Dias de Festa Nacional, 1831}

Pedro I abdicou em 7 de abril de 1831 e as comemorações subsequentes do 7 de setembro foram, inequivocamente, uma manifestação partidária, controlada pela Sociedade Defensora da Independência e Liberdade Nacional, que tem sido caracterizada pelos historiadores mais recentes como uma aliança entre grupos políticos divergentes, cuja meta era "pôr um freio na insurreição" que havia acompanhado a abdicação de Pedro. ${ }^{35}$ A Sociedade pagou por um Te Deum na igreja de São Francisco de Paula para dar graças, nas palavras de "um patriota", pela "proteção Divina", que libertou o Brasil da "ambição dos Anarquistas" e da "tirania de um déspota estrangeiro". 36 Fundos excedentes da arrecadação da Sociedade foram designados para a construção da nova prisão do Rio de Janeiro, o que um jornal aprovou entusiasticamente, "porque é certamente promovendo os bons costumes, e a moral pública, que mais eficazmente se trabalha para a liberdade da Nação." 37 Duzentos Guardas Municipais fardados (a efêmera precursora da Guarda Nacional) posicionaram-se na saída da igreja e Evaristo depois elogiou a "bela tropa de cidadãos" que asseguraram o destino do Brasil em suas mãos. Sem ter nada a ganhar com a desordem ou o despotismo, eles eram o "grande segredo para haver liberdade sem anarquia, [e] ordem sem opressão da parte dos governantes". ${ }^{38}$ Ao que parece, não ocorreram na capela imperial nem o desfile militar nem o Te Deum.

Havia algumas dúvidas sobre o significado do dia. 0 Jornal do Comércio, mesmo admitindo que Pedro I apenas havia se colocado à frente do movimento de independência em 1822 "para melhor disfrutá-la, e não perder tão rica coroa", declarou que o 7 de setembro de 1822 marcou o "primeiro passo para a Liberdade". Por essa razão, "Sete de Setembro será sempre de júbilo para os bons patriotas."39 Nessa mesma tendência, Evaristo da Veiga 
41

Jornal do Commercio, 9 de setembro de 1831; 0 Independente, 9 de setembro de 1831. Ver também Arthur Aston ao Visconde de Palmerston, Rio de Janeiro, 28 de setembro de 1831, PRO/FO 13, vol. 83, fol. 286r-v.

\section{2}

Sessões de 6, 10, e 12 de outubro, Anais da Câmara dos Deputados, 1831, vol. 2, p. 220, 229-230, 231.

43

Sessão de 11 de outubro, Anais do Senado, 1831, vol. 2, p. 259-265.

\section{4}

Decreto, 25 de outubro de 1831, CLB.

\section{5}

João Loureiro a Manuel José Maria da Costa e Sá, Rio de Janeiro, 15 de outubro de 1831. RIHGB, n.76, p.379, 1914

\section{6}

Pouco se tem escrito sobre as comemorações do Sete de Setembro. Ver, todavia, KRAAY, Hendrik. Sejamos brasileiros no dia da nossa nacionalidade: comemorações da Independência no Rio de Janeiro, 1840-1864. Topoi, Rio de Janeiro, n.14, p.9-36, janeiro-junho de 2007; MOTTA, Marly Silva da. A nação faz 100 anos: a questão nacional no centenário da Independência. Rio de Janeiro: Editora da Fundação Getúlio Vargas, 1992. p.11-22. 0 debate em torno da inauguração da estátua eqüestre de d. Pedro I em 1862 tocou em muitas das questões suscitadas pela comemoração do dia 7 de setembro. Ver, entre outros, RIBEIRO, Maria Eurydice de Barros. Memória em bronze: estátua eqüestre de D. Pedro I. In: KNAUSS, Paulo (org.). Cidade vaidosa: imagens urbanas do Rio de Janeiro. Rio de Janeiro: Sette Letras, 1999. p.15-28; SOUZA, lara Lis Carvalho. Pátria coroada: o Brasil como corpo político autônomo. São Paulo: Editora UNESP, 1998. p. 351-365. Ver também OLIVEIRA, Cecília Helena de Salles, e MATTOS, Claudia Valladão de (orgs.). 0 Brado do Ipiranga. São Paulo: Editora da Universidade de São Paulo, 1999. convocou "todos os Brasileiros que amam a pátria", "sejam quais forem os seus princípios políticos", a "se abraçarem irmamente" no dia. 40 0 Jornal do Comércio relatou vários "jantares particulares", em que "fizeram-se saúdes muito patrióticas em obséquio a este memorável dia, à Independência, à Liberdade, ao Monarca Brasileiro, o nosso anjo de paz, ao Congresso Nacional, à Regência, à União Fraternal de todos os brasileiros". Esse mesmo jornal e mais um outro lamentaram que as comemorações não foram maiores, haja vista que "o gênio do mal" havia espalhado "terror" entre os moradores da capital ao anunciar um massacre, ou uma "rusga", para o 7 de Setembro. ${ }^{41}$

Apenas no último minuto os legisladores se lembraram de que os dias de festividade nacional haviam sido estabelecidos por lei em 1826. Na véspera de 12 de outubro, a câmara dos deputados aprovou precipitadamente um projeto de lei que aboliu a data como um dia de festa nacional, instituindo o 7 de abril e o 2 de dezembro (aniversário de Pedro II) como feriados substitutos (os outros quatro feriados aprovados em 1826 permaneceram inalterados). A abdicação foi sutilmente descrita como o dia no qual a coroa foi devolvida a Pedro II. ${ }^{42} 0$ senado recebeu o projeto de lei da câmara em 11 de outubro e suspendeu os debates sobre regulamentação das faculdades de direito para lidar com a questão premente de se celebrar ou não o iminente dia de festividade nacional. A maioria concordou que seria imprudente celebrar o aniversário de Pedro I, mas vários senadores (Barbacena, Caravelas, Cairú e Vergueiro) apontaram que o 12 de outubro também era a data de criação do império e, portanto, como Caravelas colocou, "deve durar enquanto durar o Império". Quando Antônio Gonçalves Gomide afirmou que o império havia sido fundado em 7 de setembro, Caravelas explicou (corretamente) que a forma de governo - reino ou império - não havia sido decidida naquele dia. Cairú, que não era defensor da soberania popular, acrescentou, entretanto, ser o 12 de outubro o "primeiro ato explícito de exercício da soberania da Nação". Tais pontos mais delicados da história constitucional, lamentou Vergueiro, não eram percebidos pelo "povo rústico", e a população veria a comemoração do 12 de outubro simplesmente como uma manifestação restauradora. Os senadores dissertaram muito menos sobre adicionar o 7 de abril ao rol de feriados. Cairú fez essa oposição com base no fato de que nenhuma monarquia jamais comemorou uma abdicação, mas Gomide salientou que o projeto de lei propunha a celebração da aclamação de Pedro II, não da abdicação de Pedro I, o que de fato ocorreu em 6 de abril. 0 projeto de lei foi aprovado e os senadores retornaram à regulamentação dos cursos jurídicos. ${ }^{43} 0$ decreto formal, para esse efeito, apareceu somente em 25 de outubro e, consequentemente, o 12 de outubro permaneceu, com rigor factual, nos livros como um dia de festa nacional em 1831.44 Embora não houvesse celebrações oficiais do 12 de outubro na capital, um contemporâneo relatou que ocorreram alguns "jantares particulares", acompanhados de vivas a D. Pedro I". 45

\section{Conclusão}

Com a eliminação do 12 de outubro do rol dos dias de festividade nacional, o Sete de Setembro reinou supremo como o dia da independência do Brasil. 0 significado das ações de Pedro I no Ipiranga continuaria a ser debatido e as comemorações desse dia mudaram dramaticamente durante as décadas seguintes; mas o 7 de setembro nunca perdeu seu lugar como o dia em que os brasileiros celebram a independência de sua nação. ${ }^{46}$ 
47

Ver a história da campanha escrita por MELLO MORAES, Alexandre José de (pai). Monumento do Ypiranga. Brasil Historico, 17 de julho de 1864.

\section{8}

ARMITAGE, John. The History of Brazil from the Period of the Arrival of the Braganza Family in 1808, to the Abdication of Don Pedro the First in 1831. 2 vols. Londres: Smith, Elder \& Co. 1836, vol.1, p.354.

49

Presidente da Bahia a Pedro I, Salvador, 18 de setembro de 1825, Arquivo Histórico do Museu Imperial, III-POB-29.06.1825-PI.B.c.1-16.

\section{0}

TITARA, Ladislau dos Santos. Congratulação aos Brasileiros, 7 de setembro de 1828. In: Obras poeticas dedicadas à mocidade brasileira. 8 vols. Salvador: Typ. Imperial e Nacional, 18271852, vol.2, p.96-99.

\section{1}

Sobre a campanha baiana para designar o dia 2 de julho como dia de festa nacional, ver KRAAY, Hendrik. Entre o Brasil e a Bahia: as comemorações do Dois de Julho em Salvador no século XIX. Áfro-Ásia, Salvador, n.23, p.74-75, 1999. Sobre as festas civicas baianas e a pouca importância atribuida ao Sete de Setembro, ver também KRAAY, Hendrik. Definindo nação e Estado: rituais cívicos na Bahia pós Independência. Topoi, Rio de Janeiro, n.3, p.63-90, setembro de 2001

\section{2}

Raguet ao Secretário do Estado, Rio de Janeiro, 23 de setembro de 1826, NARS, M-121, rolo 7.
Neste artigo, concentrei-me no Rio de Janeiro, em detrimento do restante do pais, mas não se pode presumir que as celebrações iniciais do 7 de setembro seguiram, nas províncias, a mesma trajetória da capital. Em São Paulo, a proposta de dezembro de 1822 para a construção de um monumento no Ipiranga sugere que pelo menos alguns paulistas achavam que as ações de Pedro mereciam ser comemoradas, mesmo antes de o Sete de Setembro ter se tornado importante no Rio de Janeiro. Antônio da Silva Prado propôs a construção de um monumento em São Paulo três meses após o Grito de Pedro. Ele rapidamente recebeu a aprovação dos governos provincial e nacional para lançar uma arrecadação pública. Em 1825, a pedra fundamental para o que aparentemente se pretendia que fosse um obelisco piramidal foi colocada, mas os trabalhos cessaram em 1828, quando a arrecadação ficou muito aquém do custo projetado. ${ }^{47}$ Quando John Armitage visitou o local, em 1834, encontrou apenas fundações. ${ }^{48}$

$\mathrm{Na}$ Bahia, único estado em cujos arquivos fiz um trabalho sistemático, há apenas indicações limitadas das comemorações do Sete de Setembro durante a década de 1820. No entanto, considerando-se que pouquissimos jornais de Salvador sobreviveram, a Bahia não é o local ideal para pesquisar o início do Sete de Setembro. No tenso ano de 1824, enquanto a Confederação do Equador ainda não havia sido derrotada, o presidente da província da Bahia relatou que, no 7 de setembro, ele havia recebido aplausos no teatro, que "produziram grande efeito" e "derramaram a tranqüilidade nos ánimos." 49 Essa indicação de que ocorreram sessões de galas no teatro no 7 de setembro é confirmada pela posterior publicação de uma "Congratulação aos brasileiros", de Ladislau dos Santos Titara, recitada em gala pelo autor em 7 de setembro de 1828. Ele aclamou o Grito do Ipiranga como a origem do regime constitucional brasileiro: "Tu foste a doce origem, de onde viera/A Liberdade, e a Glória, que hoje alegre/Ao lado da ventura desfrutemos/De [sic] tí sublimes hinos dedicamos/E à Pátria, à Pedro Heroi, que idolatramos".50 A essa altura, entretanto, os baianos estavam profundamente envolvidos na celebração do aniversário de 2 de julho de 1823, quando as tropas portuguesas evacuaram Salvador, empenhando-se para transformar tal data em um dia de festividade nacional. 51

A avaliação do Sete de Setembro como a origem do regime constitucional brasileiro feita por Titara realça um último ponto importante sobre os dias de festividade nacional do Brasil imperial. Eles enfocaram principalmente os arranjos políticos do regime imperial e não incorporaram nacionalismos romântico ou étnico; a nação era uma associação política, exclusiva, é claro, cujas principais instituições - monarquia e constituição - foram estabelecidas no período de 1822-1824. Condy Raguet, provavelmente 0 representante dos Estados Unidos mais bem informado do Rio de Janeiro, captou isso de forma eficaz quando relatou a Washington que, em 1826, o parlamento decretou cinco "dias de festividade política", apesar de estar certo de que a lei os designava "dias de festividade nacional."52

Tradução: Fernanda Trindade Luciani 